ISSN (Print) : 1693-0738

ISSN (Online) : 2714-5549

Innofarm:Jurnal Inovasi Pertanian Vol. 22 (1), April 2020

\title{
PENGARUH MACAM LIMBAH RUMAH TANGGA TERHADAP PERTUMBUHAN DAN HASIL TANAMAN SORGUM MANIS (Sorghum bicolor (L.) Moench)
}

\section{Muchtarom Almutakkabbir*, Sartono Joko, Kharis Triyono}

Fakultas Pertanian, Universitas Slamet Riyadi, Surakarta

*E-mail: muchtarom96@gmail.com

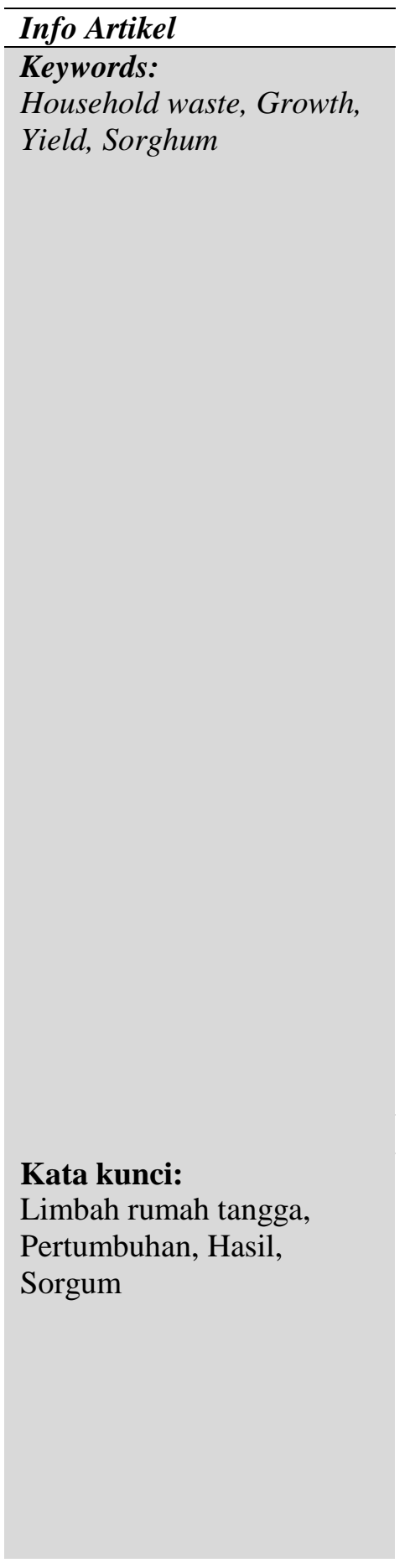

\begin{abstract}
The research about study of the effects of household waste on the growth and yield of sweet sorghum plants (Sorghum bicolor (L). Moench), with aim to know the effects of the use of household waste on the growth and yield of sweet sorghum plants (Sorghum bicolor (L). Moench), had been done from 01 October 2019 to 21 January 2020, in experimental garden of the Faculty of Agriculture, University of Slamet Riyadi Surakarta, in the village of Mojosongo, Banjarsari sub-district, Surakarta with an increase in \pm 143 places (masl). The method of research used a single Completely Random Desaign (CRD) consisting of 10 treatments, each treatment was repeated 3 times. Kind of waste household is tea water waste, coffee water waste and rice washing water waste. Data from the research were analyzed with the BNJ test (Honestly Significant Difference) at a level of 5\%. The parameters observed were included height of plant, number of leaves, length of leaves, fresh straw weight of biomass, dry straw weight of biomass, seeds totals per plant, weight dry seeds per plant, weight of 100 dry seeds per plant. The result of the research showed that : (1) the treatment of household waste that is coffee waste with a content of $50 \%$ (C1) has a significant effect on the parameters height of plant, number of leaves, length of leaves, seeds totals per plant, and weight of 100 dry seeds per plant. (2) the coffee waste treatment with a content of $50 \%$ (C1) yields the highest height of plant is 297,50 cm, the highest number of leaves is 18,83 sheet, the longest length of leaves is $146,50 \mathrm{~cm}$, the highest seeds totals per plant is 3517,33 grain, weight dry seeds per plant is 112,27 gram, and the weight of 100 dry seeds per plant is 3,79 gram. (3) the treatment that is coffee waste with a content of $50 \%$ provides the highest growth and yield in sorghum plants.
\end{abstract}

\footnotetext{
Abstrak

Penelitian ini berjudul Pengaruh Macam Limbah Rumah Tangga

Terhadap Pertumbuhan Dan Hasil Tanaman Sorgum Manis (Sorghum bicolor (L). Moench), bertujuan untuk mengetahui pengaruh penggunaan limbah rumah tangga terhadap pertumbuhan dan hasil tanaman sorgum manis, dilaksanakan mulai tanggal 01 Oktober 2019 sampai tanggal 21 Januari 2020, di Kebun Percobaan Fakultas Pertanian Universitas Slamet Riyadi Surakarta, yang terletak di Desa Mojosongo, Kecamatan Banjarsari, Surakarta dengan ketinggian tempat \pm 143 (mdpl). Penelitian ini menggunakan metode Rancangan Acak Lengkap (RAL) faktor tunggal yang terdiri dari 10 perlakuan yang masing-
} 
masing perlakuan diulang sebanyak 3 kali. Limbah rumah tangga yang digunakan yaitu limbah air teh, limbah air kopi dan limbah air cucian beras. Data hasil penelitian ini dianalisis dengan uji BNJ ( Beda Nyata Jujur ) pada taraf $5 \%$. Parameter-parameter yang diamati meliputi tinggi tanaman, jumlah daun, panjang daun, berat brangkasan basah, berat brangkasan kering, jumlah biji pertanaman, berat biji kering pertanaman, dan berat 100 biji kering. Hasil penelitian menunjukan bahwa : (1) pemberian limbah rumah tangga yaitu limbah kopi dengan kadar $50 \%$ (C1) berpengaruh nyata terhadap parameter tinggi tanaman, jumlah daun, panjang daun, jumlah biji pertanaman, dan berat 100 biji kering pertanaman. (2) perlakuan pemberian limbah kopi dengan kadar 50\% (C1) menghasilkan tinggi tanaman tertinggi yaitu $297,50 \mathrm{~cm}$, jumlah daun terbanyak yaitu 18,83 helai, panjang daun terpanjang yaitu $146,50 \mathrm{~cm}$, jumlah biji pertanaman terbanyak yaitu 3517,33 butir, berat biji kering pertanaman terberat yaitu 112,27 gram, dan berat 100 biji kering pertanaman terberat yaitu 3,79 gram. (3) pemberian limbah kopi dengan kadar 50\% (C1) memberikan pertumbuhan dan hasil tertinggi pada tanaman sorgum.

\section{PENDAHULUAN}

Sorgum merupakan tanaman pangan serealia yang mempunyai daya adaptasi tinggi yaitu lebih tahan terhadap kekeringan bila dibandingkan dengan tanaman serealia lainnya serta dapat tumbuh hampir di setiap jenis tanah. Sorgum merupakan tanaman yang sangat berpotensi untuk dikembangkan menjadi salah satu tanaman alternatif dalam memenuhi kebutuhan pangan, pakan, dan industri. Adanya peningkatan jumlah penduduk yang tidak diimbangi dengan peningkatan ketersediaan bahan pangan, dapat menyebabkan terjadinya krisis pangan. Sebagai pangan dunia sorgum berada di peringkat ke-5 setelah gandum, padi, jagung, dan barley (Sirappa, 2003).

Produksi sorgum di Indonesia masih rendah sehingga tidak masuk dalam daftar negara penghasil sorgum dunia. Data Direktorat Budi Daya Serealia pada tahun 2013 menunjukkan produksi sorgum Indonesia dalam 5 tahun terakhir hanya meningkat sedikit dari 6.114 ton menjadi 7.695 ton. Peningkatan produksi sorgum di dalam negeri perlu mendapat perhatian khusus karena Indonesia sangat potensial bagi pengembangan sorgum (Subagio dan Aqil, 2014).

Peningkatan hasil tanaman sorgum, perlu memperhatikan pemupukan. Pemanfaatan bahan limbah rumah tangga sebagai pupuk organik perlu dilakukan. Berbagai macam pupuk organik dari limbah rumah tangga diantaranya yaitu air teh, limbah air kopi dan limbah air cucian beras. teh memiliki kandungan senyawa-senyawa bermanfaat berupa kalium dan mineral yang merupakan unsur hara esensial yang dibutuhkan tanaman. Limbah kopi juga memiliki khasiat bagi tumbuhan dapat menambah asupan Nitrogen, Fosfor dan Kalium yang dibutuhkan oleh tanaman dapat menyuburkan tanah (Yunus, 2010). Air cucian beras banyak mengandung nutrisi yang terlarut didalamnya diantaranya adalah $80 \%$ vitamin $\mathrm{B} 1,70 \%$ vitamin $\mathrm{B} 3,90 \%$ vitamin $\mathrm{B} 6,50 \%$ mangan, $50 \%$ fosfor, 60\% zat besi (Nurhasanah, 2011 dalam Bahar 2016).

Berdasarkan hasil penelitian maka dapat disimpulkan bahwa uji macam pupuk hayati tanaman ubi jalar tidak berpengaruh nyata terhadap semua parameter pertumbuhan dan hasil tanaman ubi jalar yaitu panjang sulur, jumlah cabang, berat brangkasan basah, berat brangkasan kering, berat umbi, jumlah umbi, diameter umbi dan indeks panen. (Daniel Kristanto, 2019)

Penelitian ini untuk mengetahui pengaruh berbagai limbah rumah tangga terhadap pertumbuhan dan hasil tanaman sorgum manis (Sorghum bicolor (L.) Moench). Diduga penggunaan 
limbah Kopi dengan kadar 100\% memberikan pertumbuhan dan hasil yang optimal pada tanaman sorgum manis.

\section{METODE PENELITIAN}

Penelitian ini menggunakan Rancangan Acak Lengkap (RAL) faktor tunggal terdiri dari 10 perlakuan dan tiap perlakuan diulang 3 kali. Adapun perlakuannya sebagai berikut : A (Tanpa Limbah Rumah Tangga), B1 (Limbah Teh Kadar 50\%), B2 (Limbah Teh Kadar 75\%), B3 (Limbah Teh Kadar 100\%), C1 (Limbah Kopi Kadar 50\%), C2 (Limbah Kopi Kadar 75\%), C3 (Limbah Kopi Kadar 100\%), D1 (Air Cucian Beras Kadar 50\%), D2 (Air Cucian Beras Kadar 75\%), D3 (Air Cucian Beras Kadar 100\%). Selanjutnya data akan dikerjakan dengan Analisis ragam dilanjutkan uji BNJ taraf 5\%.

Bahan yang digunakan antara lain : limbah teh, limbah kopi, limbah air cucian beras, benih sorgum varietas Numbu, pupuk Urea, $\mathrm{KCl}$ dan SP-36, pupuk kandang kotoran kambing.

Alat yang digunakan yaitu : cangkul, timbangan, penggaris, rol meter, polybag, ember, gembor, alat tulis.

Penelitian telah dilaksanakan pada tanggal 1 Oktober 2019 sampai dengan 21 Januari 2020, yang dilaksanakan di kebun Percobaan Fakultas Pertanian Universitas Selamet Riyadi Surakarta, yang terletak di Desa Mojosongo, Kecamatan Banjarsari, Surakarta dengan ketinggian tempat \pm 143 meter dpl dengan jenis tanah Latosol.

Pengamatan pertumbuhan dilakukan sejak umur 1 minggu sesudah ditanam dengan interval setiap satu minggu sekali. Parameter pengamatan antara lain : tinggii tanaman, jumlah daun, panjang daun, berat brangkasan basah, berat brangkasan kering, jumlah biji pertanaman, berat biji kering pertanaman, berat 100 biji kering pertanaman.

\section{HASIL DAN PEMBAHASAN}

\section{Perumbuhan Tanaman Sorgum}

Tabel 1. Purata pertumbuhan tanaman sorgum akibat pemberian macam limbah rumah tangga

\begin{tabular}{llllll}
\hline \multirow{5}{*}{ Perlakuan } & \multicolumn{5}{l}{ Purata Hasil Pertumbuhan Tanaman Sorgum } \\
\cline { 2 - 6 } & $\begin{array}{l}\text { Tinggi } \\
\text { Tanaman } \\
(\mathrm{cm})\end{array}$ & $\begin{array}{l}\text { Jumlah } \\
\text { Daun } \\
\text { (helai) }\end{array}$ & $\begin{array}{l}\text { Panjang } \\
\text { Daun }(\mathrm{cm})\end{array}$ & $\begin{array}{l}\text { Berat } \\
\text { Brangkasan } \\
\text { Basah (gram) }\end{array}$ & $\begin{array}{l}\text { Berat } \\
\text { Brangkasan } \\
\text { Kering (gram) }\end{array}$ \\
\hline $\mathrm{A}$ & $265,50 \mathrm{~b}$ & $14,83 \mathrm{a}$ & $129,67 \mathrm{a}$ & $1416,67 \mathrm{a}$ & $642,57 \mathrm{a}$ \\
$\mathrm{B} 1$ & $261,67 \mathrm{ab}$ & $15,33 \mathrm{ab}$ & $126,00 \mathrm{a}$ & $1705,00 \mathrm{a}$ & $753,88 \mathrm{a}$ \\
$\mathrm{B} 2$ & $244,00 \mathrm{ab}$ & $14,33 \mathrm{a}$ & $124,00 \mathrm{a}$ & $1305,00 \mathrm{a}$ & $525,55 \mathrm{a}$ \\
$\mathrm{B} 3$ & $207,50 \mathrm{a}$ & $15,50 \mathrm{ab}$ & $123,67 \mathrm{a}$ & $1716,67 \mathrm{a}$ & $707,05 \mathrm{a}$ \\
$\mathrm{C} 1$ & $297,50 \mathrm{~b}$ & $18,83 \mathrm{~b}$ & $146,50 \mathrm{~b}$ & $1528,33 \mathrm{a}$ & $628,87 \mathrm{a}$ \\
$\mathrm{C} 2$ & $257,67 \mathrm{ab}$ & $15,50 \mathrm{ab}$ & $127,33 \mathrm{a}$ & $1735,00 \mathrm{a}$ & $727,45 \mathrm{a}$ \\
$\mathrm{C} 3$ & $248,50 \mathrm{ab}$ & $14,67 \mathrm{a}$ & $127,17 \mathrm{a}$ & $1323,33 \mathrm{a}$ & $684,95 \mathrm{a}$ \\
D1 & $252,83 \mathrm{ab}$ & $15,67 \mathrm{ab}$ & $126,17 \mathrm{a}$ & $1598,33 \mathrm{a}$ & $600,68 \mathrm{a}$ \\
D2 & $245,33 \mathrm{ab}$ & $15,67 \mathrm{ab}$ & $128,50 \mathrm{a}$ & $1375,00 \mathrm{a}$ & $607,93 \mathrm{a}$ \\
D3 & $264,83 \mathrm{~b}$ & $16,17 \mathrm{ab}$ & $125,17 \mathrm{a}$ & $1568,33 \mathrm{a}$ & $666,66 \mathrm{a}$ \\
\hline
\end{tabular}

Keterangan : Angka-angka yang diikuti huruf sama berarti tidak berbeda nyata pada Uji BNJ dengan taraf $5 \%$.

Tabel 1 menunjukkan bahwa pada pengamatan tinggi tanaman menunjukkan bahwa perlakuan limbah kopi kadar 50\% (C1) dengan tinggi tanaman rata-rata 297,50 cm berbeda nyata dibandingkan perlakuan pemberian limbah teh kadar 100\% (B3) dengan tinggi tanaman rata-rata 207,50 cm. 
Pengamatan jumlah daun menunjukkan bahwa perlakuan limbah kopi kadar 50\% (C1) dengan jumlah daun rata-rata 18,83 helai berbeda nyata jika dibandingkan dengan perlakuan pemberian limbah teh kadar 75\% (B2) dengan jumlah daun rata-rata 14,33 helai.

Pengamatan panjang daun menunjukkan bahwa perlakuan limbah kopi kadar 50\% (C1) dengan panjang daun rata-rata $146,50 \mathrm{~cm}$ berbeda nyata jika dibandingkan dengan perlakuan pemberian limbah teh kadar 100\% (B3) dengan panjang daun rata-rata 123,67 cm.

Pengamatan berat brangkasan basah menunjukkan bahwa perlakuan limbah kopi kadar $75 \%$ (C2) dengan berat brangkasan basah rata-rata 1735,00 gram berbeda tidak nyata jika dibandingkan dengan perlakuan pemberian limbah teh kadar $75 \%$ (B2) dengan berat brangkasan basah rata-rata 1305,00 gram.

Pengamatan berat brangkasan kering menunjukkan perlakuan limbah teh kadar 50\% (B1) berat brangkasan kering rata-rata $753,88 \mathrm{~g}$ tidak berbeda nyata dibandingkan perlakuan pemberian limbah teh kadar 75\% (B2) dengan berat brangkasan kering rata-rata 525,55 gram.

Grafik laju pertumbuhan tinggi tanaman sorgum umur 1 minggu sampai umur 12 minggu disajikan pada gambar 1 :

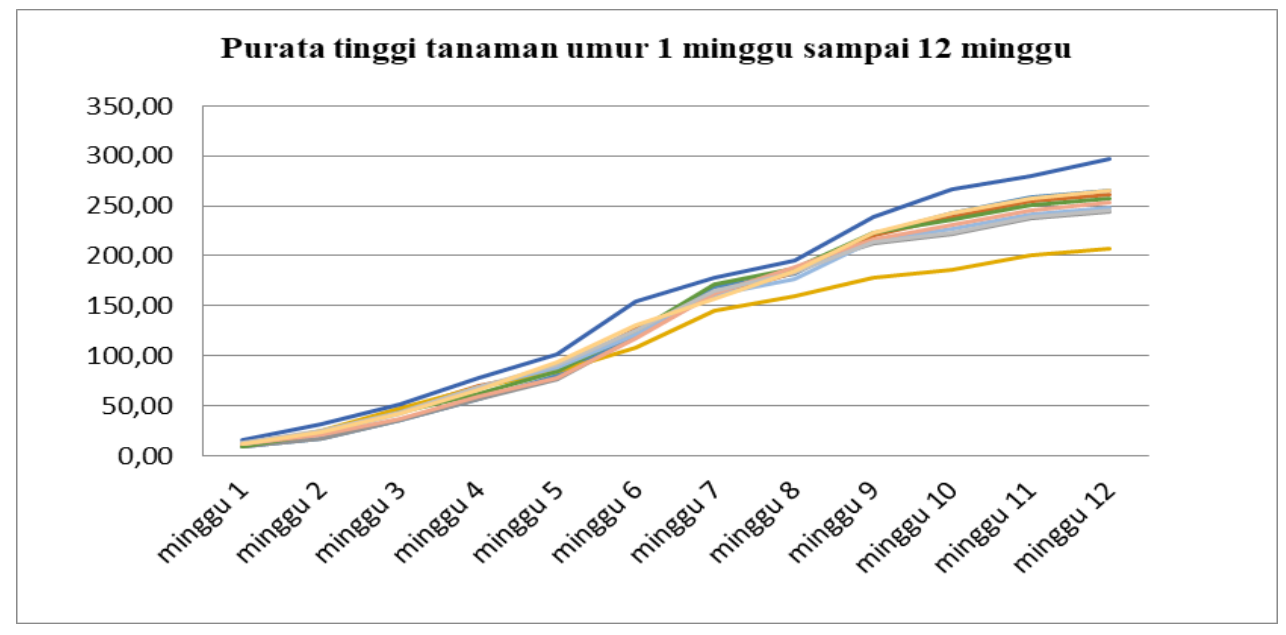

Gambar 1. Purata tinggi tanaman umur 1 minggu sampai umur 12 minggu.

Grafik laju pertumbuhan jumlah daun tanaman sorgum umur 1 minggu sampai umur 12 minggu disajikan pada gambar 2 :

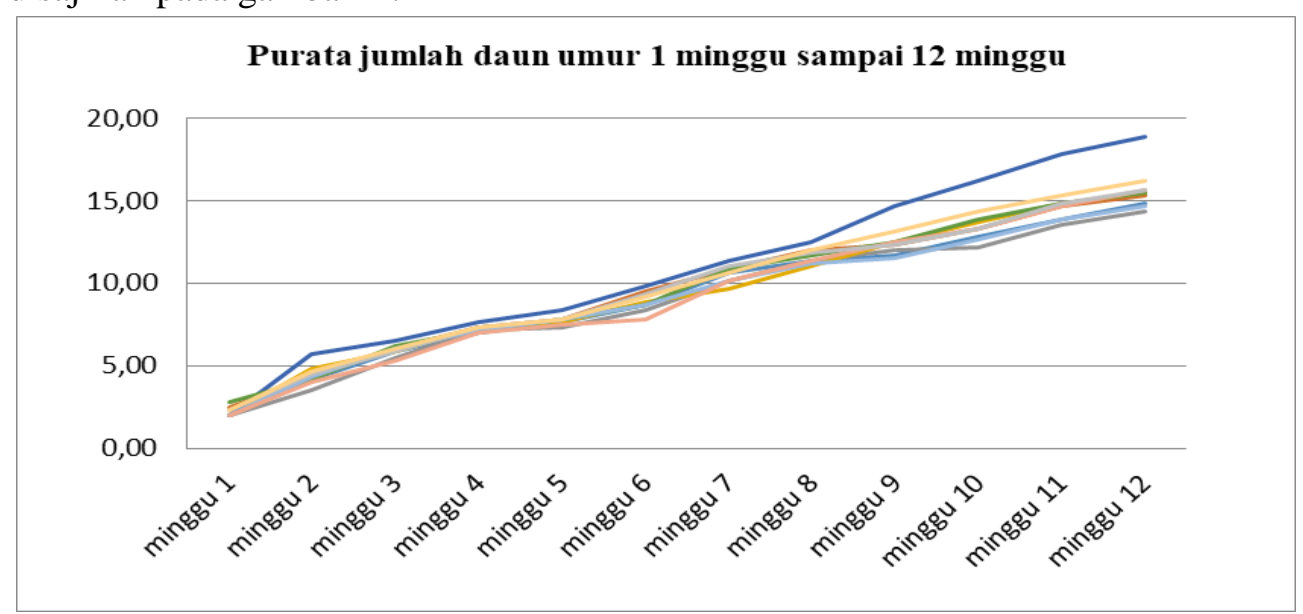

Gambar 2. Purata jumlah daun umur 1 minggu sampai umur 12 minggu. 
ISSN (Print) : 1693-0738

ISSN (Online) : 2714-5549

Innofarm:Jurnal Inovasi Pertanian Vol. 22 (1), April 2020

Grafik laju pertumbuhan panjang daun tanaman sorgum umur 1 minggu sampai umur 12 minggu disajikan pada gambar 3 :

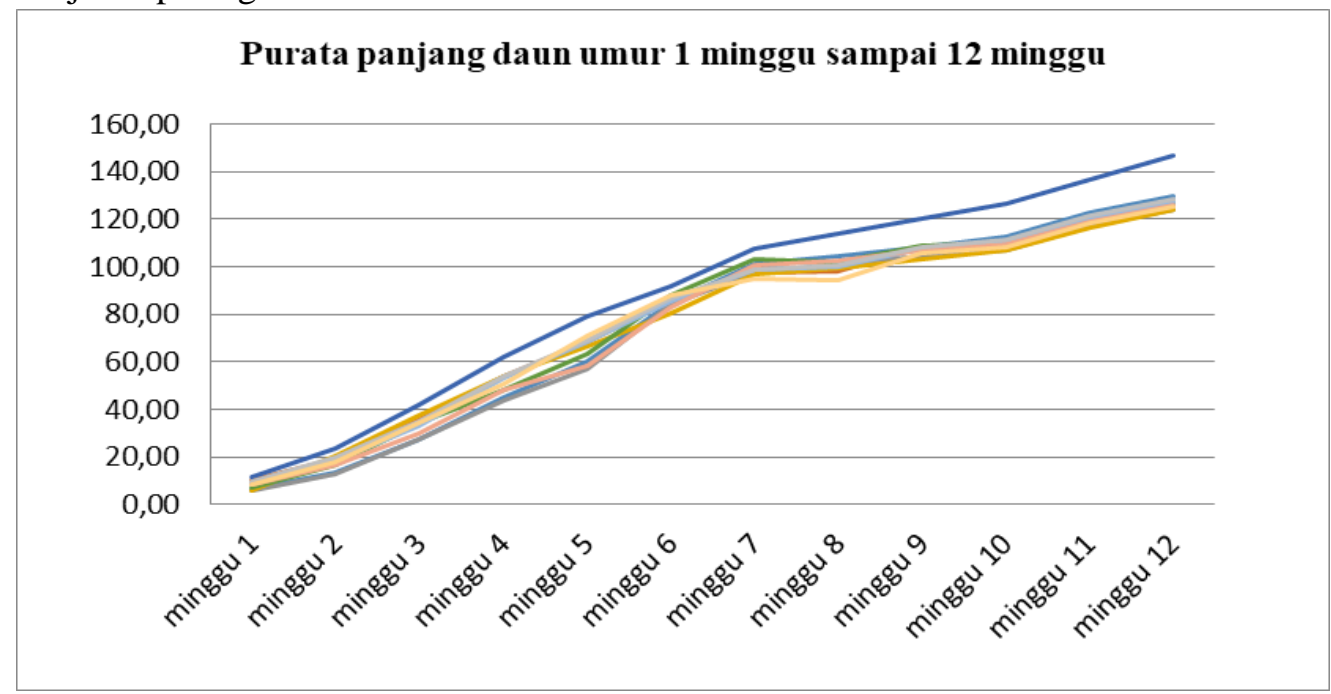

Gambar 3. Purata panjang daun umur 1 minggu sampai umur 12 minggu.

\section{A. Hasil Tanaman Sorgum}

Tabel 2. Rerata hasil tanaman sorgum akibat pemberian macam limbah rumah tangga

\begin{tabular}{llllll}
\hline \multirow{2}{*}{ Perlakuan } & \multicolumn{5}{l}{ Purata Hasil Tanaman Sorgum } \\
\cline { 2 - 5 } & $\begin{array}{l}\text { Jumlah } \\
\text { Pertanaman (butir) }\end{array}$ & $\begin{array}{l}\text { Berat Biji Kering } \\
\text { Pertanaman (gram) }\end{array}$ & $\begin{array}{l}\text { Berat 100 Biji Kering } \\
\text { Pertanaman (gram) }\end{array}$ \\
\hline A & $1713,67 \mathrm{a}$ & $57,30 \mathrm{a}$ & $2,83 \mathrm{a}$ & \\
B1 & $1985,00 \mathrm{a}$ & $70,39 \mathrm{a}$ & $2,89 \mathrm{a}$ & \\
B2 & $1428,33 \mathrm{a}$ & $55,54 \mathrm{a}$ & $3,06 \mathrm{a}$ & \\
B3 & $1530,00 \mathrm{a}$ & $53,31 \mathrm{a}$ & $2,63 \mathrm{a}$ & \\
C1 & $3517,33 \mathrm{~b}$ & $112,27 \mathrm{~b}$ & $3,79 \mathrm{~b}$ & \\
C2 & $2074,67 \mathrm{a}$ & $75,91 \mathrm{a}$ & $2,91 \mathrm{a}$ & \\
C3 & $1969,33 \mathrm{a}$ & $78,19 \mathrm{a}$ & $3,09 \mathrm{a}$ & \\
D1 & $1760,33 \mathrm{a}$ & $60,65 \mathrm{a}$ & $2,88 \mathrm{a}$ \\
D2 & $1693,33 \mathrm{a}$ & $55,26 \mathrm{a}$ & $2,71 \mathrm{a}$ & \\
D3 & $2344,33 \mathrm{a}$ & $78,34 \mathrm{a}$ & $2,81 \mathrm{a}$ & \\
\hline
\end{tabular}

Keterangan :Angka-angka yang diikuti huruf sama berarti berbeda tidak nyata pada Uji BNJ dengan taraf $5 \%$.

Tabel 2 menunjukkan bahwa pada pengamatan jumlah biji pertanaman menunjukkan bahwa perlakuan limbah kopi kadar 50\% (C1) dengan jumlah biji pertanaman rata-rata 3517,33 butir berbeda nyata jika dibandingkan dengan perlakuan pemberian limbah teh kadar 75\% (B2) dengan jumlah biji pertanaman rata-rata 1428,33 butir.

Pengamatan berat biji kering pertanaman menunjukkan bahwa perlakuan limbah kopi kadar $50 \%$ (C1) dengan berat biji kering pertanaman rata-rata 112,27 gram berbeda nyata jika dibandingkan dengan perlakuan pemberian limbah teh kadar 100\% (B3) dengan berat biji kering pertanaman ratarata 53,31 gram.

Pengamatan berat 100 biji kering pertanaman menunjukkan bahwa perlakuan limbah kopi kadar 50\% (C1) dengan berat 100 biji kering pertanaman rata-rata 3,79 gram berbeda nyata jika dibandingkan dengan perlakuan pemberian limbah teh kadar 100\% (B3) dengan berat 100 biji kering pertanaman rata-rata 2,63 gram. 


\section{KESIMPULAN}

Berdasarkan hasil penelitian dari perlakuan Pengaruh Macam Limbah Rumah Tangga

Terhadap Pertumbuhan Dan Hasil Tanaman Sorgum Manis (Sorghum bicolor (L). Moench) diambil kesimpulan :

1. Pemberian limbah rumah tangga yaitu limbah kopi dengan kadar 50\% (C1) pengaruh nyata terhadap parameter- parameter tinggii tanaman, jumlah daun, panjang daun, jumlah bijii pertanaman dan beraat 100 biji kering pertanaman.

2. Perlakuan pemberian limbah kopi dengan kadar 50\% (C1) menghasilkan tinggi tanaman tertinggi yaitu $297,50 \mathrm{~cm}$, jumlah daun terbanyak yaitu 18,83 helai, panjang daun terpanjang yaitu 146,50 $\mathrm{cm}$, jumlah biji pertanaman terbanyak yaitu 3517,33 butir, berat biji kering pertanaman terberat yaitu 112,27 gram, dan berat 100 biji kering pertanaman terberat yaitu 3,79 gram.

3. Pemberian limbah kopi dengan kadar 50\% (C1) memberikan pertumbuhan dan hasil tertinggi pada tanaman sorgum.

\section{DAFTAR PUSTAKA}

Bahar, A. E. 2016. Pengaruh Pemberian Limbah Air Cucian Beras Terhadap Pertumbuhan kangkung darat (Ipomoea reptans L.). Riau: Artikel Ilmiah Program Studi Agroteknologi Fakultas Pertanian Universitas Pasir Pengaraian

Daniel Kristanto, Priyono, Saiful Bahri. 2019. Uji Pupuk Hayati Terhadap Pertumbuhan Dan Hasil Ubi Jalar (Ipomea batatas L). Innofarm Jurnal Inovasi Pertanian Vol. 21 (2), Oktober 2019. ISSN (Print) : 1693-0738.

Sirappa, M. P. 2003. Prospek Pengembangan Sorgum di Indonesia sebagai Komoditas Alternatif untuk Pangan, Pakan, dan Industri. Jurnal Litbang Pertanian 22: 133-140.

Subagio, H. dan M. Aqil. 2014. Perakitan dan Pengembangan Varietas Unggul Sorgum untuk Pangan, Pakan, dan Bioenergi. Sulawesi Selatan. Maros: Balai Penelitian Tanaman Serealia.

Yunus, Syafrudin. 2010. Jurnalistik Terapan : Ghalia Indonesia. Bogor. 